\title{
A raspa da mandioca na alimentação das galinhas
}

\author{
A. Di Paravicini Torres \\ Seçáo de Avicultura e Cunicultura da Escola Superior \\ de Agriculiura "Luiz de Queiroz" \\ Universidade de S. Paulo
}

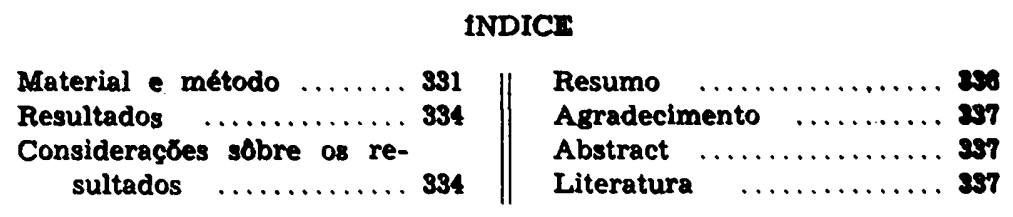


Nos climas tropicais e semitropicais, a mandioca (Manihot utilissima) constitui um recurso forrageiro de relevante impurtância pela sua elevada produção e facilidade de cultivo, fornecendo nidrocarbos ados para a alimentaçáo dos animais a um preço muitc baixo. Um alqueire de mandioca $(24.200$ mqs.) produz 50 toneladas, que rendem 20 de raspa, que avaliada a Cr.\$0,30 dí uma renda bruta de Cr.\$6.000,00 por alqueire, deixando à cultura uma boa margem de lucros e fornecendo uma forragem barata.

$\mathrm{Na}$ alimentação das aves domésticas, notadamente das galinhas, a mandioca é cortada em fatias, em máquinas especiais, ainda em estado fresco que são distribuidas para serem beliscadas. $O$ processo é trabalhoso e dificulta 0 balanço da ração, embora vantajoso noutros aspectos.

Alguns auiores têm incluido a raspa - naturalmente sob a forma de farinha - entre os alimentos indicados à composição das raçōes. Como o milho, em certas ocasiōes, atinge um preço bastante elevado, encarecendo o racionamento, propuzemo-nos a verificar se êle, como fonte de hidrocarbonados poperia ser substituido parcial ou totalmente por farinha de raspas de mandicca.

A literatura sôbre o assunto é muito escassa, talvez por náo ser a mandioca cultivada nos países onde a bromatologia avicola vem senúo mais estudada.

Nos Estados Unidos, HOLST e colaboradores (1) estudaram o farelo de mandioca ("Manioc meal") na alimentação das aves, opinando: "Aste farelo, também chamado "taploca flour" é a raiz de mandioca sêca e moída. Contém mais de 70 por cento de amido, com muito pouca proteina e minerais, é sem dúvida um concentrado energético. Ajuntado à raçăo de maneira adequada, contudo, o farelo de mandioca (raspa) serve muito bem como alimento para aves. Por causa de sua consistência farinosa, uma quantidade maior do que 10 a $15 \%$ do total la raçăo seria talvez condenável, embora proporções mais alta.s tenham sido usadas com éxito na estação experimental da Universidade da Califórnia, tanto para aves poedeiras como para pintos.

Em um trabalho sobre o farelo de raspa na alimentaçăo dos animais, KOK (2) declara que "poucas observaçoes foram feitas a respeito do uso do farelo de raspas de mandioca na alimentação das aves. Contudo, năo há aparentes contraindlcações, quanto à sua inclusão na farelada em proporçós até 20\%. Trata-se, porém, do sub-produto da fabricação da farinha de raspa de mandioca, cuja composiçáo dá e reproduzimos ao lado da composição da raspa, para comparação. 
Farelo de Raspa moida mandioca

$\begin{array}{lrr}\text { Humidade } \ldots \ldots \ldots \ldots \ldots \ldots \ldots \ldots \ldots \ldots \ldots \ldots & 12.09 & 11.79 \\ \text { Proteina } \ldots \ldots \ldots \ldots \ldots \ldots \ldots \ldots \ldots \ldots \ldots \ldots \ldots & 3.83 & 2.56 \\ \text { Matéria graxa } \ldots \ldots \ldots \ldots \ldots \ldots \ldots \ldots \ldots \ldots \ldots & 0.80 & 0.72 \\ \text { Extrativos nåo azotados } \ldots \ldots \ldots \ldots \ldots \ldots & 76.80 & \mathbf{8 1 . 5 2} \\ \text { Fibras } \ldots \ldots \ldots \ldots \ldots \ldots \ldots \ldots \ldots \ldots \ldots \ldots \ldots & 5.16 & 1.86 \\ \text { Cinzas } \ldots \ldots \ldots \ldots \ldots \ldots \ldots \ldots \ldots \ldots \ldots \ldots & 2.44 & 1.56\end{array}$

ALDO BARTHOLOMEU (3) assim se expressa sôbre o uso da mandioca na alimentaçăo das aves: "Elemento nacional de grande produção é empregado na alimentação da galinha doméstica numa porcentagem de 5 a 10 por cento sôbre o total de raçáo balanceada. Cultivada em terrenos não muito bons, exigindo tratos culturais baratos, é elemento indispensável, principalmente àqueles que criam marrecos, perús para corte ou capões para engorda".

Na Baí, PITHON (4) relata o emprêgo da mandioca e subprodutos de sua indústria na alimentação de pintos e galinha, com bons resultados, chamando especialmente a atençăo para a presença de vitaminas do complexo $B$, já constatada há muitos anos por GODOY, nesta Escola. Sôbre o mesmo assunto CAMPOS (5) realizou interessantes e mais completos trabalhos quer com raspas, quer com mandioca crua e cozida. As raspas possuem, segundo êste autor, boa quantidade de vitamina B1 (tiamina), mas não a flavina do complexo B2, presente em elevada taxa na mandioca crua. Em outro trabalho (6) demonstra a existência do fator antipelagroso, B6.

\section{MATERIAL E METODO}

A raspa utilizada foi por nós obtida e trabalhada na Seção de Avicultura, não tendo porém sido analisada, adotandose a composição indicada por REIS (7) de $2,8 \%$ de proteina bruta, 84,1 de hidrocarbonados, 0,2 de matérias graxa e 5,0 de fibras. Essa composiçáo não difere muito daquela apresentada por outros autores ( 8 e 1), salvo no teor de fibras que parece exagerado.

$\begin{array}{lrrrrrr}\text { Autor } & \text { Agua } & \text { Proteina } & \text { Hidrocarbonados } & \text { Graxa } & \text { Fibra } & \text { Cinza } \\ (8) & 15.00 & 3.04 & 77.76 & 0.53 & 1.90 & 1.77 \\ & 15.00 & 3.80 & 70.00 & 0.50 & 2.20 & 2.00 \\ & 15.00 & 2.80 & 74.50 & 0.60 & 1.90 & 1.80 \\ & 15.00 & 2.50 & 76.00 & 0.50 & 1.60 & 1.50 \\ (1) & & 2.10 & 81.50 & 0.40 & 1.60 & \end{array}$


Foram organizados 3 lotes de pintos de 6 semanas aproximadamente de idade, aparentemente machos e colocados em baterias especiais, da seguinte forma :

Lote A - 10 "Light Sussex" e 10 "Rhode Island Red" (testemunha).

Lote B - 20 "Sussex - Substituição de 50\% do milho por raspa.

Lote C - 20 "R I. R." - Substituição total do milho por raspa.

Sabendo por observações anteriores que os pintos da raça "Light Sussex" e "R. I. R." comportam-se diferentemente no crescimento, achámos que poderiam reagir de maneira diversa no aproveitamento da raspa, dai termos formado o lote testemunha com 10 pintos de cada raça, constituindo sub-lotes que neste trabalho receberam o prefixo respectivamente de SA E RA.

As raçóes utilizadas foram as seguintes :

\section{Lote A - Testemunha - Sem raspa}

$\begin{array}{rlcccr} & \text { Proteinas } & \text { Hidrocarb. } & \text { Fibras } & \text { Graxas } \\ 30 \text { kgs. de farelo de trigo } & 4.68 & 16.53 & 2.70 & 0.57 \\ 50 \text { kgs. de fubá de milho } & 4.75 & 35.60 & 1.05 & 2.10 \\ 10 \text { kgs. far. torta algodåo } & 4.18 & 2.71 & 1.14 & 0.64 \\ 10 \text { kgs. far. de carne 40\% } & 4.00 & 0.18 & 0.21 & 1.19 \\ \text { Totals } & 17.61 & 55.02 & 5.12 & 4.40\end{array}$

Lote B - Substituição de $50 \%$ do milho por raspa de mandioca e farinha de carne

Proteinas Hidrocarb. Fibras Graxas

$\begin{array}{llrrrr}30 \text { kgs. de farelo de trigo } & 4.68 & 16.53 & 2.70 & 0.57 \\ 25 \text { kgs. de fubá de milho } & 2.38 & 17.80 & 0.52 & 1.05 \\ 22 \text { kgs. raspa de mandioca } & 0.61 & 18.50 & 1.10 & 0.04 \\ 10 \text { kgs. de torta de algodáo } & 4.18 & 2.71 & 1.14 & 0.64 \\ 14,5 \text { kgs. far. de carne 40\% } & 5.80 & 0.26 & 0.30 & 1.59 \\ \text { Totais } & 17.65 & 55.80 & 5.76 & 3.89\end{array}$

Lote C - Substituição total do milho por raspa de mandioca e farinha de carne

Proteinas Hidrocarb. Fibras Graxas

$30 \mathrm{kgs}$. de farelo de trigo 4.68

$\begin{array}{llll}4.68 & 16.53 & 2.70 & 0.57\end{array}$

$44 \mathrm{kgs}$. raspa de mandioca 1.22

10 kgs. de torta de algodăo 4.18

37.00

$2.20 \quad 0,08$

$18 \mathrm{kgs}$. farinha de carne $40 \% \quad 7.20$

2.71

1.14

0.64

$\begin{array}{lll}0.32 & 0.37 & 1.96\end{array}$

Totais 17.28

56.56

6.41

3.25 
As quantidades de farelo de trigo e de torta de sementes de algodão permaneceram constantes nas tres raçóes. Como dada quantidade de fubá de milho não pode ser substituida por idéntica de raspa, por ser esta multo mais pobre em proteina, tornou-se necessária a elevação do teor farinha de carne para manter mais ou menos constante a porcentagem de proteina bruta, que em nossas raçóes fica próxima de $17.5 \%$. A ligeira inferioridade na quantidade total de proteinas e graxas da raçáo C năo seria de molde a prejudicar a experiência. Essas raçoes foram completadas com farinha de ostra, sal e verduras.

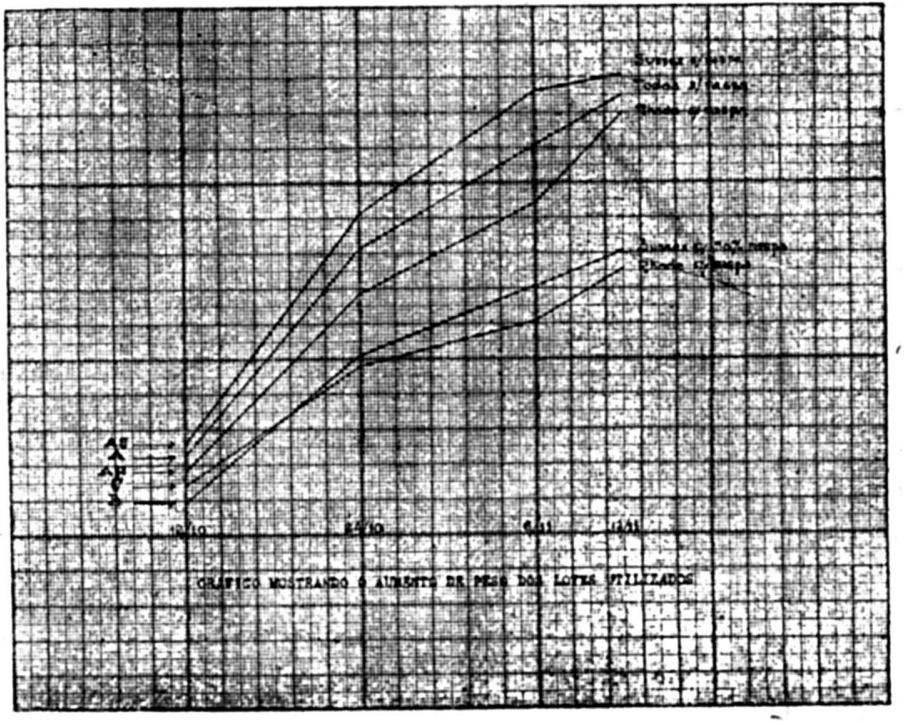

A experiência foi iniciada no dia 12-10-45, realizando-se mais três pesagens, respectivamente nos dias 24-10, 6-11 e 12-11, năo tendo podido prolongar-se porque a gaiola de reclusăo tornou-se inadaptada. As pesagens foram feitas de manha em jeJum, em balança de precisão de um grama. 


\section{RESULTADOS}

Os pesos e outros resultados nas 4 pesagens nos Lotes A, B e C foram os seguintes:

\begin{tabular}{|c|c|c|c|c|}
\hline Lote & 1.a Pesada & 2.a Pesada & 3.a Pesada & 4.a Pesada \\
\hline A & $862.5 \pm 129$ & $1155 \pm 160$ & $1302 \pm 156$ & $1377 \pm 142$ \\
\hline $\mathbf{B}$ & $796.7 \pm 131$ & $1005 \pm 120$ & $1103 \pm 113$ & $1154 \pm 122$ \\
\hline $\mathbf{C}$ & $824.7 \pm 77$ & $988 \pm 245$ & $1052 \pm 107$ & $1128 \pm 116$ \\
\hline AS $(*)$ & $882.0 \pm 101$ & $1215 \pm 132$ & $1381 \pm 118$ & $1402 \pm 301$ \\
\hline AR (**) & $843.0 \pm 155$ & $1096 \pm 169$ & $1223 \pm 153$ & $1350 \pm 391$ \\
\hline
\end{tabular}

Calculado o t-test dividindo-se a diferença das médias pelo êrro da diferença, observou-se o seguinte resultado :

T-test observado

\begin{tabular}{ccccc}
\hline Comparação & 1.a Pesada & 2.a Pesada & 3.a Pesada & 4.a Pesada \\
\hline A - B & 1.55 & 3.35 & 4.62 & 5.35 \\
A - C & 1.12 & 2.55 & 5.91 & 6.09 \\
B - C & 0.82 & 0.28 & 1.42 & 0.70 \\
AS - AR & 0.66 & 1.76 & 2.58 & 0.34 \\
AS - B & 1.96 & 4.23 & 6.15 & 2.51 \\
AR - C & 0.35 & 1.41 & 3.15 & 1.76 \\
\hline
\end{tabular}

NOTA:- Em negrito, valores significativos.

\section{CONSIDERAÇOES SOBRE OS RESULTADOS}

Náo obstante os lotes organizados para a experiencia năo serem absolutamente homogêneos, a variação existente entre suas médias não chega a ser significativa, estatisticamente falando, pois os valores de $\mathbf{t}$ da diferença das médias de todos os grupos encontra-se abaixo do valor máximo de $5 \%$ de probabilldade de serem equivalentes.

(*) 10 Sussex do Lote A.

(**) 10 Rhode do Lote A. 
Já no fim do $1 .^{\circ}$ periodo, na $2 . a$ pesagem, constata-se uma grande vantagem em favor do Lote $\mathbf{A}$, vantagem essa significativa. Considerando-se as raças isoladamente, tal năo chegou a se verificar apenas com o lote de Rhode testemunha AR em relaçăo ao Lote $\mathbf{C}$, porém na 3.a pesada, não só se agravou a diferença já existente entre as médias do Lote A com os demais, como a diferença do Lote $A R$ em relação ao $C$ chegou a ser bastante significativa.

Em relação à $4 . a$ pesagem, os resultados sáo mantidas, confirmando a superioridade da ração do lote $A$, exceto para as "Rhode" tomados isoladamente, que reagiram no Lote $C$, tomando um impulso. Esse aumento mais ativo entre a $3 . a \mathrm{e}$ 4.a pesadas dos "Rhode" pode ser explicado, pelo fato já observado, que, em idade mais avançada, os pintos aproveitam melhor uma alimentação inferior, principalmente quando foram submetidos anteriormente a um regime de carência.

Entre os Lotes B e C náo houve diferença significativa em nenhuma das pesagens de forma que tanto faz substituir metade como todo o milho por raspa de mandioca na raçáo que o prejuizo no aumento de peso é o mesmo.

Observou-se ainda que as duas raças utilizadas na experiencia comportam-se diferentemente, aumentando a "Sussex" mais ràpidamente de pesso no principio, chegando a diferença de pêso entre as raças ( $t$-test $=2.58$ ) a ser significativa na $3 . \mathrm{a}$ pesada. Essa diferença, todavia, desaparece na 4.a pesada, porque o aumento de peso dos "Rhode", embora menos intenso, permaneceu constante como se pode observar pelo quadro apresentado mais adiante. Estes últimos resultados estáo de acordo com outros por nós obtidos em trabalho ainda inédito.

Damos abaixo o aumento médio diário verificado nos 3 periodos, durante a experiência :

\begin{tabular}{|c|c|c|c|c|c|}
\hline \multirow{2}{*}{ 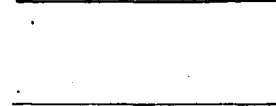 } & \multicolumn{2}{|r|}{ Lote A } & \multicolumn{2}{|r|}{ Lote B } & \multirow{2}{*}{$\frac{\text { Lote C }}{\text { Sussex }}$} \\
\hline & Sussex & Rhode & Todos & Rhode & \\
\hline No 1.0 periodo & 27.75 & 21.1 & 24.3 & 18.2 & 13.6 \\
\hline No $2 .^{\circ}$ período & 13.80 & 10.6 & 12.3 & 8.2 & 5.4 \\
\hline No $3 .^{\circ}$ período & 3.70 & 21.2 & 12.5 & $8.5^{\circ}$ & 12.7 \\
\hline Nos 3 períodos & 17.4 & 16.9 & 17.1 & 12.2 & 10.1 \\
\hline Aumento \% & 59.1 & 60.1 & 59.6 & . 46.6 & 36.7 \\
\hline
\end{tabular}


Considerando-se 0 aumento relativo de peso verifica-se que - aumento de peso dos "Rhode" e "Sussex" com a raçăo A foi praticamente igual e que o Lote $B$ em relaçăo a A sofreu um prejulzo de $13 \%$ e o Lote $\mathrm{C}$ de $23 \%$.

Pelo comportamento verificado nos aumentos dos Lotes B e C seria de se esperar uma reaçáo nas semanas subsequentes, que tenderia a diminuir a diferença com A. So uma experiencla por um periodo mais longo poderia revelar se pode ou năo ocorrer uma reagăo posterior prevista nestes resultados.

Devemas ainda mencionar que o volume da raçăo consụmida fol praticamente igual nos 3 lotes e que as raçoes com mandioca eram bastante palatáveis, sendo bem apreciadas pelos plntos.

Avaliando-se o preço do quilograma de raspa num terço do valor do quilo de milho, o custo da raçăo, exceto verduras, fol o seguinte :

$$
\begin{aligned}
& \text { Raçåo A - Cr.\$ } 0,70 \text { o quilo } \\
& \text { Raçåo B - Cr.\$ } 0,60 \text { o quilo } \\
& \text { Raç๕o C - Cr.\$ } 0,48 \text { o quilo }
\end{aligned}
$$

Os aumentos totals de peso nos lotes tendo sido respec!1vamente de:

$$
\begin{aligned}
& \text { Raçăo A } 27530 \text { grs. }-17250=10280 \text { grs. } \\
& \text { Raçăo B } 23080 \text { grs. - } 15935=7145 \text { grs. } \\
& \text { Raçăo C } 22550 \text { grs. }-16495=6055 \text { grs. }
\end{aligned}
$$

O custo relativo do racionamento pode ser determinado dividindo-se o custo em centavos da unidade de peso de cada racáo pelo aumento em gramas verificado durante a experiencia.

$$
\begin{array}{lll}
\text { Ração A } & 70 / 10280=0 & =0.0068 \\
\text { Raçåo B } & 60 / 7145 & =0.0084 \\
\text { Raç\$o C } & 48 / 6055=0.0079
\end{array}
$$

Do que se conclui que a raçăo de fubá de milho, embora mais cara, produz um aumento de peso mais barato, sendo portanto mats economica que a substituiçăo parcial ou mesmo tota.l

\section{RESUMO}

Tres lotes de pintos de 6 semanas de Idade foram submetidas a uma experiencia de alimentaçáo, durante o periodo de um mes, para se verificar se o milho duma determinada raço 
poderia ser substituido parcial (50\%) ou totalmente por farinha de raspa de mandioca.

Embora os pintos das raçóes com raspa de mandioca comessem com avidez, e tivessem tido um crescimento aparentemente normal, sem revelar carencias alimentares, o lote testemunha alimentado sem raspa teve um aumento de peso significativamente bem maior, o que indica que a mandioca năo pode substituir o milho sem desvantagem. A raçăo de mandioca aparentemente mais barata, torna-se mais cara quando se determina o custo da unidade do aumento de paso.

Os dados colhidos parecem indicar contudo que se a allmentaçăo perdurasse por mais algum tempo poder-se-ia verificar uma reaça nos pintos alimentados com raspa de mandioca, o que dependeria de ulteriores verificaçбes.

\section{AGRADECIMENTO}

Registramos um agradecimento especial ao Dr. E. A. Graner pela assistencia prestada na análise estatistica dos resultados.

\section{ABSTRACT}

In this paper the author studies the partial and total substitution of ground corn by ground dried cassava. Three rations of $17.5 \%$ of protein were given to six week chicks during four weeks : one ration contained only corn, other $50 \%$ of corn and $50 \%$ of cassava and in the third the corn was entirely substituted by cassava meal. After 30 days the rations including cassava showed smaller weight of the chicks. No injury was observed in the animals and the difference between the two rations with cassava was not significant but both proved to be significantly different of the control.

\section{LTTERATURA}

(1) HOLST, W. F. e NEWLON, W. E., 1935 - Poultry Feeding : Principles and Practice, revisto por H. J. ALQUIST e T. H. JUKES, Bol. 417, Univ. da California, Berkeley.

(2) KOK, E. A. 1943 - O farelo de raspas de mandioca na allmentaçáo dos animais - Ol. 35 - S. V. - Dep. P. Animal, Sžo Paulo.

(3) BARTHOLOMEU, A., s/data - Conjunto de Liçoes sobre Criaçáo de galinhas, etc. "Sítios e Fazendas" edit. sao Paulo. 
(4) PITHON, E. P., 1940 - A Avicultura na Bala, Conferencia, in "O Campo", n. 132, pp. 66/9, Rio de Janeiro.

(5) CAMPOS, F. A. de Moura, 1937 - Complexo vitaminico B na Mandioca, A. F. Med U. S. Paulo XIII, pp. 33, 8. Paulo.

(6) CAMPOS, F. A. de Moura, 1941 - Mandioca como fonte de Vitamina B6, Arq. C. C. e Exp. V, pp. 203, Så Paulo.

(7) REIS, J., 1944 - Criaçăo de Galinhas, Ediçoes Melhoramentos, S. Paulo.

(8) FERREIRA F. 0 , J. C. e cols., 1942 - Manual da Mandioca, "Chac. e Qu." edit., Sžo Paulo.

(9) BRIEGER, F. G., 1937 - Tábuas e Fórmulas para Estatistica, Melhoramentos edit., Såo Paulo. 